\title{
Unique Case Series of Occipital Sinus and Its Thrombosis- A Radiological Marvel
}

\author{
R. Harikiran Reddy ${ }^{\oplus 1}$, Pooja Subramanya ${ }^{\circledR 2}$, Joish Upendra Kumar ${ }^{\oplus 3}$, B. Gurumurthy ${ }^{\odot 4}$, J Punya ${ }^{\oplus 2}$, C. M Sahana ${ }^{\circledR 2}$ \\ ${ }^{1}$ MDRD, Assistant Professor, Department of Radiology, J.J.M. Medical College, Kuvempu Nagar, Davanagere, Karnataka, India, ${ }^{2}$ MDRD, Junior Resident, Department of \\ Radiology, J.J.M. Medical College, Kuvempu Nagar, Davanagere, Karnataka, India, ${ }^{3}$ MDRD, Assistant Professor, Department of Radiology, K.V.G. Medical College,, Sullia, \\ Karnataka, India, ${ }^{4}$ Consultant Radiologist, Department of Radiology, J.J.M. Medical College, Kuvempu Nagar, Davanagere, Karnataka, India.
}

\section{Abstract}

Background: Variations of the dural venous sinuses may result in inaccurate imaging interpretation or complications during surgical approaches. One of these variations reported infrequently is the occipital sinus with an overall incidence of under $10 \%$. When present, it may get thrombosed or become source of intracranial bleeds or pose difficulty during occipital craniotomies. Our review suggests that the thrombosis of this unique venous sinus variant is a rare condition as there are very few case reports of the same. Herein, we present a case series of persistent occipital sinus and the unusual combination of a persistent occipital sinus and its thrombosis. Subjects and Methods: The study included 4 paediatric cases that presented with neonatal seizuressecondary to different underlying aetiologies and in retrospect had either persistent andpatent occipital sinus or a thrombosed occipital sinus. A descriptive study of the aforementioned cases was carried out. MRI scanner PHILIPS Achieva 1.5 Tesla was used for diagnosis. Results: One case had thrombosis of bilateral persistent occipital sinuses and superficial cortical veins with minimal intraventricular haemorrhage in bilateral lateral ventricles.Second case had persistent and thrombosed right occipital sinus; while two other cases had persistent but patent occipital sinuses. Conclusion: A comprehensive knowledge of cerebral venous anatomy and meticulous recognition of venous variations essentially helps when dealing with a pathology, which presents along with a particular venous variation, no matter how rare this combination is.

Keywords: Occipital sinus, thrombosis, MRI.

Corresponding Author: Pooja Subramanya, MDRD, Junior Resident, Department of Radiology,, J.J.M. Medical College, Kuvempu Nagar, Davanagere, Karnataka, India.

E-mail: poojansb@gmail.com

Received: 05 December 2020

Revised: 13 January 2020

Accepted: 20 January 2020

Published: 30 May 2020

\section{Introduction}

Variations of the dural venous sinuses may result in inaccurate imaging interpretation or complications during surgical approaches. One of these variations reported infrequently is the occipital sinus. ${ }^{[1]}$

In a study, persistent occipital sinuses were seen in only $13 \%$ of patients $<25$ months of age with a further decease in incidence to $2 \%$ in children older than 5 years. ${ }^{[2]}$ Another study including patients ranging from 9 days to 83 years, showed the incidence to be $10 \%{ }^{[3]}$

When present, it may get thrombosed or become source of intracranial bleeds (clival epidural hematomas) or pose difficulty during occipital craniotomies. ${ }^{[4,5]}$

Our review suggests that the thrombosis of this unique venous sinus variant is a rare condition as there are very few case reports of the same. Herein, we present a case series of this unusual combination of a persistent occipital sinus and its thrombosis.

\section{Subjects and Methods}

The study included 4 paediatric cases that presented with neonatal seizures secondary to different underlying aetiologies and in retrospect had either persistent and patent occipital sinus or a thrombosed occipital sinus. A descriptive study of the aforementioned cases was carried out.

MRI scanner PHILIPS Achieva 1.5 Tesla was used for diagnosis.

3D T1, T2 TSE axial/ coronal/saggital, T2 FFE, TOF MRV, DWI, FLAIR axial, T1 IR sequences were included for evaluation. 
Results

\section{Case 1 [Figure 1]}

Showed thrombosis of bilateral persistent occipital sinuses and superficial cortical veins with minimal intraventricularhemorrhage in the occipital horn of bilateral lateral ventricles

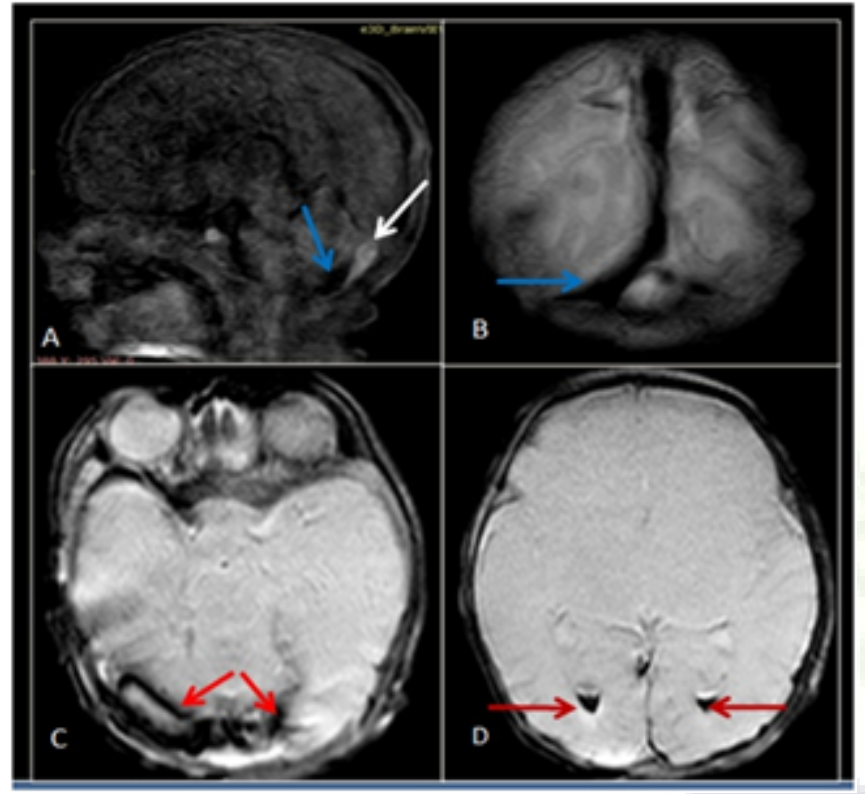

Figure 1: A:T1 saggitalview: Blue arrow showing patent transverse sinus. :White arrow showing loss offlow void in thrombosed occipital sinus. B: T1 coronal view: Blue arrow showing patent transverse sinus. C: Axial T2 FFE: Red arrows pointingtowards blooming within thrombosed bilateral occipital sinuses. D:Axial T2 FFE: Red arrows pointingtowards blooming within the occipital horns of bilateral lateral ventriclessuggestive of intraventricular haemorrhage.

\section{Case 2 [Figure 2]}

Showed a persistent right occipital sinus which was thrombosed.

\section{Case 3 [Figure 3]}

Showed bilateralpersistent and patent occipital sinuses.

Discussion

Anatomy

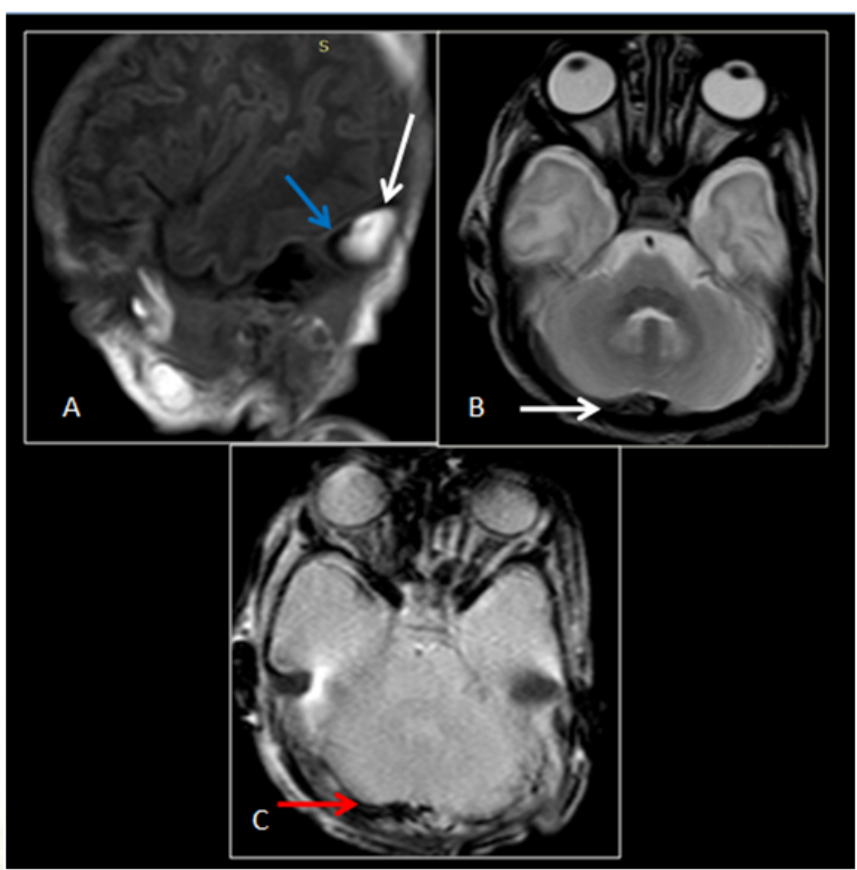

Figure 2: A:T1 saggital view: Blue arrow showing patent transverse sinus: White arrowshowing loss of flow void in thrombosed occipital sinus. B: T2 axial view: White arrow showing loss offlow void in the right occipital sinus. C: Axial T2 FFE: Red arrows pointing towards blooming within thrombosedright occipital sinus.

Occipital sinus is the smallest of the dural venous sinuses and lies in the attached margin of the falx cerebella communicating with the torcularherophili, superiorly, and with the vertebral venous plexus and marginal sinus, inferiorly. at the foramen magnum. ${ }^{[6-9]}$ Occasionally, instead of running in the midline, the occipital sinus deviates to one side to join the sigmoid sinus as it passes through the jugular foramen and has been termed the oblique occipital sinus. ${ }^{[10,11]}$ If such a deviated occipital sinus is large, it may prove hazardous in approaches to the posterior cranial fossa. ${ }^{\left[{ }^{1,12]}\right.}$ Tributaries may include veins of the hypoglossal canal, basilar plexus, occipital emissary, and diploic veins. ${ }^{[7]}$ It shows several variations, and functions as the main drainage canal when the lateral sinus is rudimentary. It should be emphasized that before posterior fossa operations one should know these variations. ${ }^{[13]}$

\section{Embryology}

Developmentally, the dural venous sinuses emerge as venous plexuses and exhibit a variable degree of plexiform arrangement, rather than the single luminal structure found in the majority of sinuses ${ }^{[14]}$ It should be noted that the occipital venous network is thought to become involuted once most of the venous flow passes through the large dural sinuses as the 


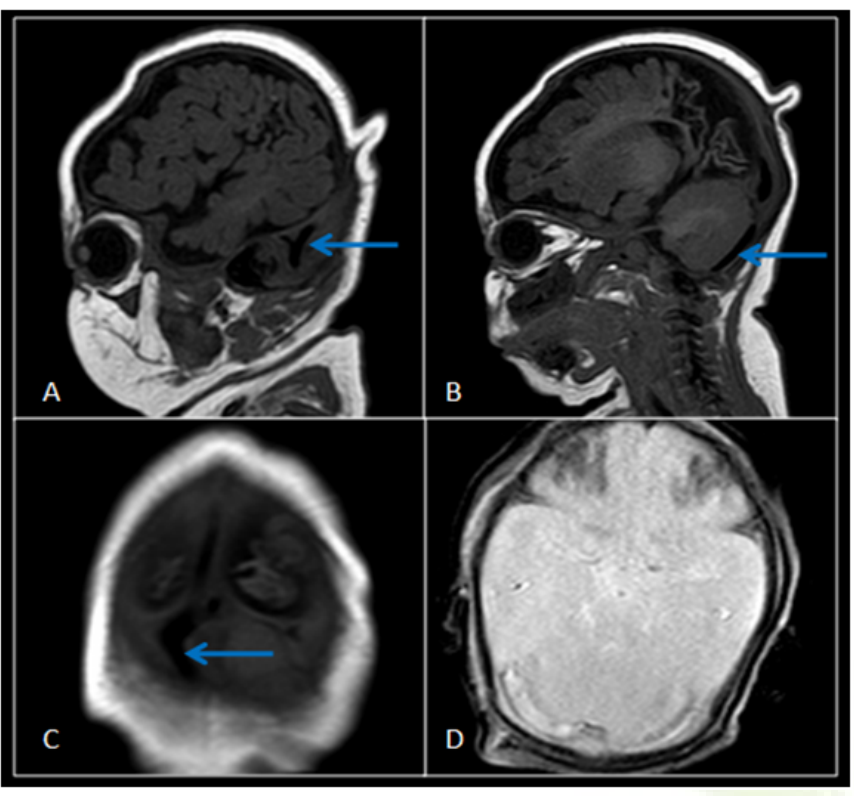

Figure 3: A)T1 saggital view: Blue arrow showing patent occipital sinus. B)T1 saggital view: Blue arrow showing patent transverse sinus. C)T1 coronal view: Blue arrow showing patent occipital sinus. D) Axial T2 FFE: No focus of blooming at the level of the visualised occipital sinuses.

child achieves an upright position. ${ }^{[1]}$ This is in concordance with the incidence of $13 \%$ of patients $<25$ months of age with a further decease in incidence to $2 \%$ in children older than 5 years and an overall incidence of $10 \%$ in general population further, it is found to be relatively wider in neonates than in adults. ${ }^{[2,3,11]}$

\section{Significance}

When present, occipital sinus may get thrombosed or become source of intracranial bleeds (clival epidural hematomas) or pose difficulty during occipital craniotomies. ${ }^{[4,5]}$

Dural sinus thrombosis (DST) is a disease entity in which early diagnosis can make an important difference with regards to patient outcome. Inability to correctly diagnose DST can occasionally allow the disease to progress to a critical state manifested by cerebral infarction, impaired consciousness, coma, and death. In one recent study, a substantial average delay of 7 days between the onset of symptoms and imagingbased diagnosis was found. ${ }^{[15]}$

A combination of the presence of this rare venous variant and its thrombosis thus can go easily missed if not looked for religiously.

\section{Conclusion}

A comprehensive knowledge of cerebral venous anatomy and meticulous recognition of venous variations essentially helps when dealing with a pathology, which presents along with a particular venous variation, no matter how rare this combination is.

\section{References}

1. Beyrouti R, Mansour M, Kacem A, Zaouali J, Mrissa R. Occipital Sinus Thrombosis: An Exceptional Case Report. J Stroke Cerebrovasc Dis. 2016;25(6):71-73. Available from: https://dx.doi.org/10.1016/j.jstrokecerebrovasdis.2016.02.006.

2. Rollins N, Ison C, Booth T. MR venography in the pediatric patient. Am J Neuroradiol. 2005;26:50-55.

3. Ayanzen RH, Bird CR, Keller PJ. Cerebral MR venography: normal anatomy and potential diagnostic pitfalls. Am J Neuroradiol. 2000;21(1):74-78.

4. Guillaume D, Menezes AH. Retroclival hematoma in the pediatric population. Report of two. cases and review of the literature. J Neurosurg. 2006;105((4 Suppl)):321325. Available from: https://dx.doi.org/10.3171/ped.2006.105. 4.321.

5. Tubbs RS, Bosmia AN, Shoja MM, Mariosloukas JK, Curé AA, Cohen-Gadol. The oblique occipital sinus: A review of anatomy and imaging characteristics. Surg Radiol Anat. 2009;33(9):747-749. Available from: https://dx.doi.org/10. 1007/s00276-011-0831-9.

6. Patel N. Venous anatomy and imaging of the first centimeter. Semin Ultrasound CT MR. 2009;30(6):513-524. Available from: https://dx.doi.org/10.1053/j.sult.2009.08.003.

7. Lang J. Clinical anatomy of the posterior cranial fossa and its foramina. New York: Thieme; 1991.

8. Kobayashi K, Suzuki M, Ueda F, Matsui O. Anatomical study of the occipital sinus using contrast-enhanced magnetic resonance venography. Neuroradiology. 2006;48(6):373-379. Available from: https://dx.doi.org/10.1007/s00234-006-0087y.

9. Srijit D, Lativ AA, Suhaimi FH, Othman FB, Yahaya MF, Ahmad F. An anatomico-radiological study of the grooves for occipital sinus in the posterior cranial fossa. Bratisl Lek Listy. 2008;109(11):520-524.

10. Tubbs RS, Shojamm, Loukas M. An unusual finding of the posterior cranial fossa: one case report. Ital J Anat Embryol. 2008;113:83-86.

11. Lang J. Clinical anatomy of the posterior cranial fossa and its foramina. In: The floor of the posterior cranial fossa. New York: Thieme; 1991. p. 6-9.

12. Costa D, Krishnamurthy S, Nayak A, Madhyasta SR, Prabhu S, Jiji LV, et al. Duplication of falxcerebelli, occipital sinus, and internal occipital crest. Rom J Morphol Embryol. 2009;50:107110.

13. Dora F, Zileli T. Common variations of the lateral and occipital sinuses at the confluens sinuum. Neuroradiology. 1980;20(1):23-27. Available from: https://dx.doi.org/10.1007/ bf00346857.

14. Bisaria KK. Anatomic variations of venous sinuses in the region of the torcular Herophili. J Neurosurg. 1985;62(1):9095. Available from: https://doi.org/10.3171/jns.1985.62.1. 
0090.

15. Ferro JM, Canhão P, Stam J, Bousser MG, Barinagarrementeria F, Massaro A. Delay in the diagnosis of cerebral vein and dural sinus thrombosis: influence on outcome. Stroke. 2009;40(9):3133-3138. Available from: https://doi.org/10. 1161/strokeaha.109.553891.

Copyright: (C) the author(s), 2020. It is an open-access article distributed under the terms of the Creative Commons Attribution License (CC BY 4.0), which permits authors to retain ownership of the copyright for their content, and allow anyone to download, reuse, reprint, modify, distribute and/or copy the content as long as the original authors and source are cited.

How to cite this article: Reddy RH, Subramanya P, Kumar JU, Gurumurthy B, Punya J, Sahana CM. Unique Case Series of Occipital Sinus and Its Thrombosis- A Radiological Marvel. Asian J. Med. Radiol. Res. 2020;8(1):44-47.

DOI: dx.doi.org/10.47009/ajmrr.2020.8.1.9

Source of Support: Nil, Conflict of Interest: None declared. 